\section{Document Micro-reproduction}

"Mrcrotexts as Media for Publication" (Hertfordshire County Council Technical Information Service, Hatfield. 9s.) records the papers and discussion of a symposium held at Hatfield Technical College in November 1959. The organizers are to be congratulated on getting as main speakers three of the best known names in the microtext field-Mr. Eugene Power, of University Microfilms, Inc., who spoke about successes achieved with microfilm, particularly in the academic field; Dr. L. J. van der Wolk, director of the library of the Delft Technical University, on the increasing use of microfiche (that is to say, flat film, $75 \times 125 \mathrm{~mm}$. or $90 \times 120 \mathrm{~mm}$., containing 8-100 pages); and Mr. C. D. Gelatt, on the 'Microcard'. The experts in three forms of document micro-reproduction have not previously been heard together in Great Britain, and it is noticeable that there is no feeling of competition between them; each believes that there is a place for his particular form of microtext. The booklet also reproduces a delightful talk given in London early in 1959 by Fremont Rider, whose book, "The Scholar and the Future of the Research Library", originally published in 1944, suggested 'Microcards' to the library world. The idea was taken up by $\mathrm{Mr}$. Gelatt, who was and is an industrialist in Wisconsin. He endowed the Microcard Foundation with 100,000 dollars, and the success of the idea is apparent when we remember the millions of 'Microcards' being made for the International Geophysical Year and the Atomic Energy Commission. (This booklet's 88 pages are reproduced on two 'Microcards' placed in a pocket on the inside of the back cover.) The pamphlet will be of great interest to librarians and others concerned with the newer ways of publishing and photocopying.

\section{Radiochemistry of the Elements}

The Subcommittee on Radiochemistry of the Committee on Nuclear Science of the United States National Academy of Sciences (National Research Council) is sponsoring a series of monographs on the radiochemistry of the elements, three volumes of which, on cadmium, arsenic and francium, have now been issued (National Academy of Sciences-National Research Council. Subcommittee on Radiochemistry. NAS-NS-3001: The Radiochemistry of Cadmium. By James R. DeVoe. Pp. vi +57.75 cents. NASNS-3002: The Radiochemistry of Arsenic. By Harold C. Beard. Pp. vi +27.50 cents. NAS-NS3003: The Radiochemistry of Francium. By Earl K. Hyde. Pp. vi + 34. 50 cents. Washington, D.C. : Office of Technical Services, Department of Commerce, 1960). It is expected that about fifty volumes will be issued within the next six months.

\section{Preventive Aspects in the Teaching of Pathology}

IN the past the practice of medicine was almost. wholly, if not altogether, confined to the treatment of patients. Nowadays, the doctor is often called upon to apply his knowledge for the prevention of disease. This change in medical practice is being increasingly recognized by the medical schools with the introduction of preventive medicine and social medicine into the curriculum, not as an isolated subject, but as one integrated with the other disciplines. In 1957 a Study Group was convened by the World Health Organization to consider how the preventive aspects of medicine could be introduced into the teaching of physiology. A similar task has now been undertaken for pathology by the Expert Committee on Professional and Technical Education of Medical and Auxiliary Personnel (World Health Organization. Technical Report Series No. 175 : Preventive Aspects in the Teaching of Pathology-Seventh Report of the Expert Committee on Professional and Technical Education of Medical and Auxiliary Personnel. Pp. 30. (Geneva : World Health Organization; London: H.M. Stationery Office, 1959.) I Swiss franc; $18.9 d . ; 0.30$ dollar). In its report, the Committee points out that the essential task of the teacher of pathology in promoting the concept of prevention is to trace the complete evolution of lesions, paying special attention to their causation, their progressive development, and the disturbances in function that they bring about. He is in a particu. larly advantageous position to show the stages in the progress of the disease at which the changes are still reversible, and so the limits beyond which efforts at prevention and cure become increasingly less effective.

\section{Semiconductor Components}

THE front cover of the 1959 annual report of Texas Instruments, Inc, consists of a full colour photomicrograph showing the crystal structure of a high-purity bismuth telluride bar made during thermoelectric experiments in the Texas Instruments Central Research Laboratories (Texas Instruments, Inc. Annual Report, 1959. Pp. 20. Dallas: Texas Instruments, Inc., 1960). The report states that during 1959 the company continued its pattern of rapid growth and improvement of operations, with an increase of 110 per cent in sales and 136 per cent in net income over the previous record. The total personnel increased from 7,500 to 15,000 . Three new buildings were completed on the 300 -acre estate in North-east Dallas, and an addition to the semiconductor-components plant and a building for the manufacture of basic semiconductor and other materials are under construction. During September the construction of a new 120,000 -sq. ft. plant was begun at Bedford, England, for Texas Instruments. Ltd., a subsidiary company, which manufactures semiconductor devices for the markets of the United Kingdom and Western Europe. The plant will be completed late this year and will augment the 35,000 -sq. ft. factory now in use. The work of the Metals and Controls Division and of the Geosciences and Instrumentation Division is briefly described and illustrated in the report. In addition, the revolutionary new solid eircuit semiconductor introduced in March 1959 is discussed. This product represents a new approach to electronic circuitry and component miniaturization, providing an entire circuit in a single-crystal semiconductor slab no larger than a mateh head. Nearly a dozen different types of circuits have already been produced and many more can be constructed using the existing techniques. The first applications are to computers. missiles, rockets and space vehicles.

\section{Acoustic Tiles for Noise Control}

$\mathrm{IT}_{\mathrm{T}}$ is sometimes possible to make considerable improvements by controlling noises at their sources. In the many cases where this cannot be done, soundabsorbing materials can be used to reduce noise to an acceptable level. Investigations in the Architectural Physics Section of the Division of Building Research of the Commonwealth Scientific and Industrial Research Organization, Highett, Victoria, 